\title{
THE NEED OF ADEQUATE BASIS FOR CONTROL OF FOREST REGENERATION
}

\author{
By A. KoROLEFF ${ }^{1}$
}

T HE NEED to assure consistently, in the course of forest utilization, prompt and proper regeneration with desirable species is a serious challenge to our profession. Planting is fine where needed and when its rather high cost can be justified - not sufficiently often, judging by its very limited application. Our main problem, however, is not artificial regeneration but effective and cheap provision for good natural restocking of our forests.

Let us leave aside "economic factors", often given as obstacles to more rapid solution of this problem. Let us see whether adequate silvicultural knowledge is available for sound practice when and where the "green light" can be given by the economic situation.

It is elementary that the kind of growth that follows a certain kind of logging is determined by the reaction of competing forms of vegetation to the conditions created by that particular form of logging. To know how different forest species-valuable or "weeds"- -will react to a given form of cutting, and what sort of regeneration we will get under certain chosen logging practices, we must know enough about the silvicultural requirements of each of these species.

The aim of this article is to emphasize the fact that it does not suffice to know, merely in terms of their species, the requirements of forest trees to such basic ecological factors as light, water, heat, etc. These requirements change throughout the life of a tree. We must have sufficient information with regard to each major stage of development of that species, from seed germination to maturity-especially for the germination and seedling stages. ${ }^{2}$

To be able to control natural restocking of our forests, we must have this data not only for the species we want to regenerate but for each competitor. Otherwise, even where the economic factors could permit adequate provisions for good restocking, the results will be good, bad or indifferent, as the case may be. Unless proper, timely efforts are made in their favour, some of our best species often reproduce not nearly as readily as some of inferior value, or even "weeds". Therefore, considerable deterioration of our forests is apt to result if appropriate steps to prevent it are not taken.

The innate characteristics of tree species and the chosen logging practice are usually the two main factors which decide the issue of reproduction after cutting, even though this issue also may be affected by geographic and site factors. I need not deal here with the latter relationship as it has been very

1. The ideas expressed in this article are given by me as a member of the forestry profession, entirely unofficially. My employers, the Canadian Pulp and Paper Association and the Pulp and Paper Research Institute of Canada, have no responsibility whatsoever for the contents of this article.-A. Koroleff.

2. Let us remember that pork and beans may be good for a grown-up man but would not do for a new-born baby. 
ably presented by G. A. Pearson in his recent article, "How Local is Silviculture?" On my suggestion it is reprinted in this issue immediately follow. ing this item. That article is deserving of careful study also on account of its excellent, concise reference to silvicultural characteristics of ponderosa pine, by its growth stages. In substance and form it exemplifies the information which, I think, we need for our forest trees, as a clear'cut guide for prac. tice of silviculture.

How much do we know about silvicultural requirements of our trees and their changes with the main stages of their lives? Those of our leading foresters with whom I have had occasion to discuss this matter feel, almost without exception, that there is a definite and regrettable shortage of this knowledge. This shortage, not unnatural in a country where forestry is still so young, certainly is large when contrasted with the situation in some of the older foreign countries. Although under serious circumstantial handicap for making an inquiry, the writer recently made an attempt to obtain from a number of eastern Canadian foresters their ideas on optimum silvicultural requirements of white spruce, black spruce, balsam, jack pine, white birch and poplar-for each of their growing stages (germination, seedlings, saplings, poles and standard). The questionnaire form was prepared with the most helpful co-operation of W. M. Robertson, Chief of Silvicultural Research, Dominion Forest Service, Ottawa. It was as follows:

\section{QUESTIONNAIRE}

:Re OPtimum Silvicultural Requirements For (species) ........

(Kindly fill in this form FULiY, but mark a cross (x) after each individuab reply that expresses a guess or a belief rather than definite knowledge.)

Please code your replies in the appropriate columns below, as follows:

Soil Moisture

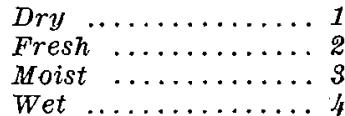

Light

Full light $\ldots \ldots \ldots \ldots 1$

Partial shade .......

Deep shade ....... 8

Optimum ReQUiRements

\section{Local Climate}

Hot-dry ........... 1

Warm-damp ........2

Cool-dry ........... \&

Cool-damp ..........

\begin{tabular}{|c|c|c|c|c|}
\hline \multirow{2}{*}{$\begin{array}{c}\text { Growing } \\
\text { Stage }\end{array}$} & \multirow{2}{*}{$\begin{array}{c}\text { Soil } \\
\text { Moisture }\end{array}$} & \multicolumn{2}{|c|}{ Light } & \multirow{2}{*}{$\begin{array}{c}\text { Local } \\
\text { Climate }\end{array}$} \\
\hline & & $T o p$ & Side & \\
\hline \multicolumn{5}{|c|}{ Germination } \\
\hline \multicolumn{5}{|l|}{ Seedling } \\
\hline \multicolumn{5}{|l|}{ Sapling } \\
\hline Poles & & & & \\
\hline standard & & & & \\
\hline
\end{tabular}


Best kind of soil?...............Does best growth for final crop occur in pure stands?............ or in mixture with?.............

Conditions on forest floor particularly favourable for seed germination of the

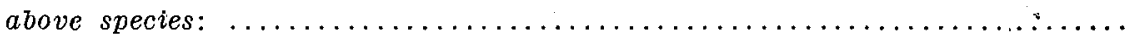

Particularly unfavourable for seed germination: $\ldots \ldots \ldots \ldots \ldots \ldots \ldots \ldots \ldots$

Conditions on the forest floor particularly favourable for survival and growth

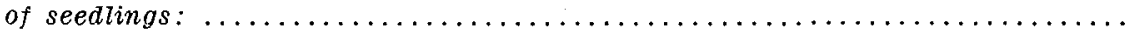

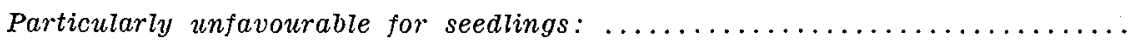

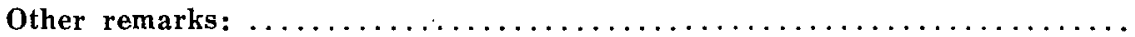
District ................... and province

to which the above applies.

(Note: for economy of space in the publication, blank spaces provided in. this form for the reply have been abbreviated.)

Only 17 out of 70 foresters to whom the questionnaire was sent, have filled it in; several replied that they lack the information; most have not replied.

The summary of the 17 replies with regard to optimum requirements, of the 6 species mentioned for soil moisture, light and local climate, by growth stages is given in Table 1, the figures in the table being arithmetic averages for all replies.

The individual replies on the subject referred to in the table have shown in most cases considerable or great variation. This applies in general also to answers to the other questions which will be dealt with in a subsequent article. I hope that, in line with previous tentative understanding, the arrangements will be made not only for a more complete study of the questionnaire material by an agency that has suitable facilities, but for its thorough consideration in the light of pertinent research data, such as has been obtained by the Dominion Forest Service. It is probable that the research so far conducted in this country cannot adequately satisfy practicing foresters as to the guiding information on control of forest regeneration. If so, additional research will be indicated and should be arranged without delay.

Meanwhile, our silvicultural research agencies could help our foresters by compiling and issuing in clear-cut form a summary of their practical findings to date on control of forest regeneration.

The object of this article, and of our questionnaire, is not to provide a basis for proper direction of natural regeneration of our forests. That obviously would be beyond the writer's ability. The object is to attract the attention of those concerned in silviculture to the importance and urgency of a thorough, systematic inquiry into the matter, and of making the resulting data available to all those who stand in need of it.

We can hardly hope to make sustained yield forest management a reality and a success if dependent on control of forest regeneration "by guess and by God". That control must be firmly placed on a scientific basis. 


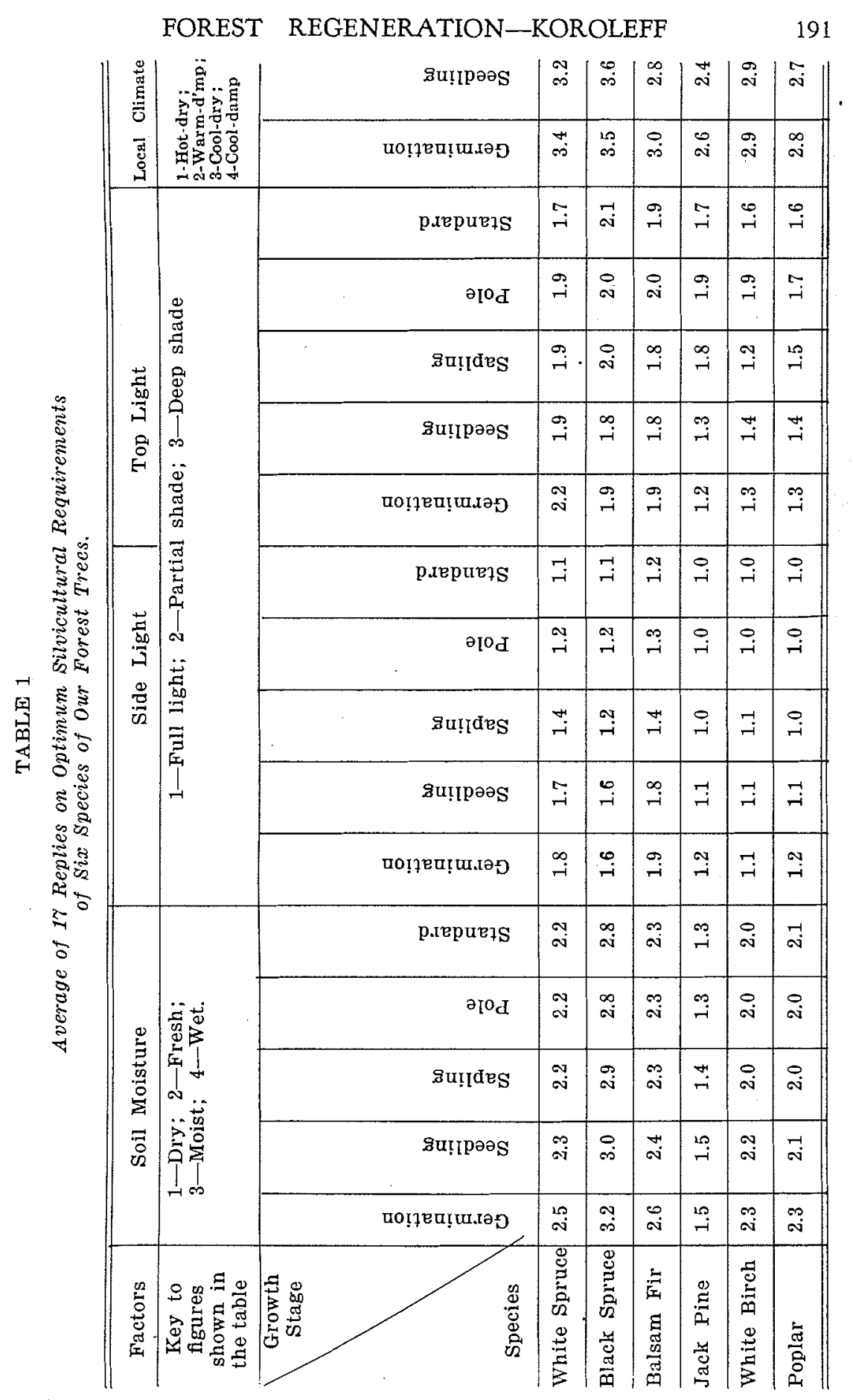

